\title{
COVID-19 and the role of e-cigarette use: An evidence-based review
}

\author{
İsmet ÇOK ${ }^{1}$ * (D) , İrem İYİGÜNDOĞDU 1 (D), Mesut YILDIRIM 1,2 (D) \\ 1 Deparment of Toxicology, Faculty of Pharmacy, Gazi University, Hipodrom 06330, Ankara, Turkey. \\ 2 Department of Radiology, Etimesgut Şehit Sait Ertürk State Hospital, Etimesgut 06790, Ankara, Turkey. \\ * Corresponding Author. E-mail: ismetc@gazi.edu.tr (İ.Ç.); Tel. +90-312-202 3089.
}

Received: 28 April 2021 / Revised: 01 July 2021/ Accepted: 05 July 2021

\begin{abstract}
While the world is grappling with one of the biggest pandemics in history, the role that personal preferences or lifestyles can play in the development of this pandemic should not be overlooked. One of these preferences is the use of electronic cigarettes (e-cigarettes). COVID-19 is a disease that primarily attacks the lungs. Thus, factors that cause pre-existing lung disease such as e-cigarette use may increase the risk for critical complications from COVID-19. Promoted as an alternative to conventional cigarettes, e-cigarettes induce inflammation of human airways and possibly increase susceptibility toward pneumonia because of an increase of pneumococcal adherence to airway cells. Lung damage caused by flavorings contained in e-cigarettes can increase health risks, especially from COVID-19. When compared to nonsmokers, e-cigarette users had a five times increased risk while dual users with tobacco had a seven times increased risk of COVID-19 infection. Recent research supports that many medical consequences such as lung inflammation and increased susceptibility to pulmonary viral and bacterial infections in smokers and people with COVID-19 disease may also develop due to e-cigarette use. The aim of this article is to investigate whether there is a role for e-cigarette use in the development of respiratory diseases caused by the COVID-19 virus. With the help of our experience of working on e-cigarettes for many years and various scientific databases (PubMed, Scopus, etc.), the health risks experienced by people who both use e-cigarettes and have a COVID-19 virus infection, and the role of respiratory system symptoms, in particular, were investigated.
\end{abstract}

KEYWORDS: SARS-CoV-2; COVID-19; electronic cigarette; EVALI.

\section{INTRODUCTION}

The main problems of humanity, including climate change and global warming; air, water and soil pollution; population growth estimated to exceed nine billion by 2050; loss of biodiversity; microplastics; energy sustainability; excessive consumption of resources and waste management; lack of food; and poverty have almost been replaced with the threats of coronavirus disease 2019 (COVID-19) that has affected all societies and caused the death of more than 1 million people in a short time. Humanity's current main goal is to develop vaccines and drugs that can defeat COVID-19 as soon as possible. In other words, humanity is trying to save the day by ignoring the traditional large-scale threats that will gradually destroy itself, for which they were seeking a solution until a year ago.

The pandemic of COVID-19, troubling the world for more than a year, is caused by a novel severe acute respiratory syndrome coronavirus 2 (SARS-CoV-2). Besides the systemic symptoms such as fever, fatigue, and myalgia, several upper and predominantly lower respiratory tract symptoms including dry cough, sore throat, sneezing, rhinorrhea, dyspnea, chest pain, and respiratory problems develop after infection with SARS-CoV2. In addition, acute respiratory distress syndrome (ARDS), hypoxemia, shock, arrhythmia, acute cardiac injury, and acute renal failure have been observed among COVID-19 patients [1]. The disease might lead to shortness of breath, possibly accompanied by or progressing to hypoxemia for some patients. The development of ARDS from respiratory injury is a feared complication that occurs in 10-20\% of severe cases. Also, non-cardiogenic pulmonary edema and a requirement for mechanical ventilation might be encountered in some patients. Interestingly, many of these conditions also resemble the health risks that can be seen in long-term smokers. Risk factors for disease severity are underlying comorbidities (for instance, hypertension, cardiovascular diseases, diabetes, and cerebrovascular disease) and advanced age [2]. Furthermore, lifestyle factors such as smoking and obesity might be a key factor in the progression of the disease. How to cite this article: Cok I, lyigundogdu I, Yildirim M. COVID-19 and the role of e-cigarette use: An evidence-based review. J Res Pharm.
$2021 ; 25(6): 815-822$. 
According to the Centers for Disease Control and Prevention (CDC), smokers are at increased risk of severe COVID-19 illness as well as adults of any age with certain underlying medical conditions such as cancer, chronic obstructive pulmonary disease (COPD), chronic kidney disease, coronary artery disease or cardiomyopathies, cardiac diseases such as heart failure, immunodeficiency from solid organ transplantation, sickle cell disease, obesity, pregnancy, and type 2 diabetes mellitus. The first systematic review examining five studies from China by Vardavas and Nikitara concluded that smoking is most likely associated with the progression and negative outcomes of COVID-19 as noted in previous influenza and MERS-CoV outbreaks. [3]. Furthermore, Patanavanich and Glantz, as a result of their meta-analysis to determine the relationship between COVID-19 and cigarette smoking, reported that "smokers have about 2 times the odds of severe COVID-19 outcomes than never smokers" and concluded that cigarette smoking was an independent risk factor for disease progression [4]. The banned sales of tobacco products during the lockdown periods to mitigate the COVID-19 pandemic in countries such as South Africa and India clearly reveal the negative role of tobacco products in this pandemic [5]. With an increasing number of scientific data on the role of cigarettes in COVID-19, the question arises whether e-cigarettes, the consumption of which is escalating in societies, also have a detrimental effect on the disease caused by the COVID-19 virus.

\section{E-CIGARETTES}

During the last decade, the tobacco and cigarette industry has been in an effort to introduce new products to the market against the measures taken by the governments, especially against cigarettes, and the most popular product among these new products has been e-cigarettes [6]. The variety of products called ecigarettes is changing daily and different products are included in this range. Most of these new products utilize heating instead of burning, some use nicotine liquids, and some use specially prepared tobacco itself, similar to cigarettes. For example, "Ploom", "IQOS", "Ifuse", "Glo", and "JUUL" are the trade names of these products and they are offered to nicotine addicts with different mechanisms (fired, heated, etc.). Studies investigating the number and diversity of chemical substances released by e-cigarettes report that the level of toxic compounds in e-cigarette vapor is lower compared to conventional cigarettes [7,8]. The interpretation of this situation as "not being exposed to any chemicals or carcinogenic substances" due to e-cigarette use is misleading consumers and the general public in terms of health risks that may arise.

Scientific studies demonstrated the presence of carbonic compounds, volatile constituents, especially acetaldehyde, tobacco-specific nitrosamines, phenolic compounds, tobacco alkaloids, flavorings, illicit drugs (e.g., Tetrahydrocannabinol-THC), and at least 20 human carcinogens and teratogens such as formaldehyde, benzaldehyde, acrolein, and polycyclic aromatic hydrocarbons in e-liquids and e-cigarette vapor [9]. Today, there is substantial evidence showing that vitamin $\mathrm{E}$ acetate and heavy metals such as lead and arsenic are important components of some e-cigarettes [10]. Our knowledge of the health effects of e-cigarette exposure is still in its infancy and the consequences of chronic exposure are undetermined. In this environment of uncertainty, our lack of information about the extra health risks that COVID-19 may pose in e-cigarette users prevents the optimal management of the disease.

E-cigarettes have gained popularity among adults and adolescents worldwide. For example, approximately 3 million high school age adolescents and over 10 million adults are active electronic nicotine delivery system (ENDS) users in the USA and this number is increasing daily [11]. Adolescents constitute a risk group with the greatest increase in use. For example, e-cigarettes were the most commonly used tobacco product among high school students $(11.7 \%)$, followed by cigars $(7.7 \%)$, cigarettes $(7.6 \%)$, smokeless tobacco $(5.5 \%)$ and hookah (3.3\%) in 2017 in USA [12]. The findings of the 2018 National Youth Tobacco Survey conducted in the USA indicates as a high popularity of e-cigarette usage among high school youth, increasing up to $75 \%$ between 2017 and 2018 [13].

\subsection{E-cigarettes and lung diseases}

Since the introduction of e-cigarettes to the marketplace, it has been suggested that the inhalation of various toxic compounds and microparticles produced by the vaping process could cause damage to the lungs. Various health effects are expected, especially on the respiratory system, due to e-cigarette use. The first evidence that the usage of e-cigarettes could lead to a serious and life-threatening lung disease was revealed with isolated lung injury reports starting in 2012 [14]. Other studies, especially studies in adolescents, have begun to reveal a relationship between bronchitis symptoms (chronic cough, sputum production, or bronchitis) and the frequency of e-cigarette use $[15,16]$. 
Today we have a growing body of epidemiological data from several cross-sectional studies that have found associations between respiratory symptoms and e-cigarette use. These studies report an increase in the prevalence and severity of symptoms in asthma, especially among adolescents, due to e-cigarette use. According to a survey, conducted in Hong Kong with participitation of approximately 45.000 adolescents, recent usage of e-cigarette of previous month was associated with an increased odds of reporting chronic cough or sputum (odds ratio 2.1, 1.8 to 2.5) [16]. Results of a study on 2.086 students, who are attending final grades of high school (11th and 12th grade) based in Southern California show that both current and past use of e-cigarettes is associated with a nearly two-fold increase in the risk of chronic bronchitis symptoms (bronchitis chronic, cough or phlegm,). Another survey of 35.904 Korean high school students found that, after adjusting for potential confounders like exposure to cigarette smoke, student's self-reported doctor diagnosis of asthma in the past 12 months increased in current e-cigarette users compared to those who never used it (odds ratio 2.7, 1.3 to 5.8). Additionally, this study has proven the fact that e-cigarette usage also trigers asthma severity, which causes absence from school due to asthma symptoms [17]. The researchers conducted a cross-sectional survey on covariates and smoking with participitation of 8.087 Hawaiian adults through random dialing on telephone in 2016. According to those surveys, serious links of chronic pulmonary disorder in the total sample of e-cigarette users were detected [18]. A cross-sectional study of a random sample of 30.272 Swedish adults found an association of e-cigarette use with respiratory symptoms such as long-standing cough, recurrent wheezing. Moreover, the prevalence of respiratory symptoms was highest among the current smokers who also used e-cigarettes [19]. After 142 cases reported from Illinois and Wisconsin related to ecigarette and vaping-product use associated lung injury (EVALI) was first described in 2019 by the CDC [20]. Furthermore, different cross-sectional surveys have found associations of e-cigarette use with a history of asthma and with asthma exacerbations in young people in USA [21,22]. According to the study, conducted by Health eHeart with participation of 40.000 individuals, usage of e-cigarette increases case numbers of dyspnea and reports of asthma and COPD [23].

Recently, various studies have revealed the damage caused by the use of e-cigarettes to the respiratory system. These studies have shown that exposure to vapour of e-cigarettes can disrupt pulmonary homeostasis with increased airway inflammation, oxidative stress and risk of respiratory infection, decreased lung function and immunity. [15,18,24-26]. Moreover, e-cigarettes cause a significant induction of inflammation in the lungs through a different dysregulated immune landscape. Thus, in addition to tobacco, e-cigarettes can also worsen the inflammation in COVID-19 [27] and might cause an increased susceptibility toward pneumonia due to the facilitation of pneumococcal adherence to airway cells. Furthermore, e-cigarettes could cause damage to lung epithelium (Table 1) [28]. Among various types of e-cigarettes, those containing nicotine and flavors are related to oxidative stress, epithelial barrier dysregulation, DNA damage, and enhanced inflammation [27].

Table 1. Effects of e-cigarette/e-liquids on the lung.

\begin{tabular}{lcccc}
\hline Effects & Endothelia & Epithelia & Fibroblasts & $\begin{array}{c}\text { Tissue/cell type } \\
\text { cells BALF }\end{array}$ \\
\hline Cytotoxicity & $\downarrow$ & $\uparrow$ & $\uparrow$ & \\
Cell Viability & $\downarrow$ & $\downarrow$ & $\uparrow$ \\
Infection & & $\uparrow$ & & \\
Inflamation & & $\uparrow$ & & $\uparrow$ \\
Electrical Resistance & $\downarrow$ & & & $\uparrow$ \\
Cytokine Secretion & & & & \\
Macrophages & & & $\checkmark$ & \\
Altered morphology & & & & \\
\hline
\end{tabular}

Madison et al. (2019) [11] demonstrated in animal studies that e-cigarette exposure, independent of nicotine, caused changes in lipid metabolism and profiles in alveolar macrophages and epithelial cells. They have found aberrant phospholipids in alveolar macrophages and an increase in surfactant-associated phospholipids in the airways. In addition to e-cigarette-induced lipid deposition, chronic e-cigarette vapor exposure downregulates innate immunity against viral pathogens in those macrophages. Also in the extension of their study, e-cigarette exposed mice infected with influenza virus demonstrated augmented and persistent tissue damage and lung inflammation, independent of nicotine, resulting in increased morbidity and mortality. E-cigarette vapor aberrantly changes the physiology of local immune cells and lung epithelial cells and leads to a weak response against infectious agents. Since the alterations in immune dysfunction and lipid homeostasis also take place in the absence of nicotine, more comprehensive studies of the vehicle solvents 
used in e-cigarettes are warranted, which were considered safe until recently and are still not evaluated by regulatory authorities.

\section{COVID-19 AND E-CIGARETTES}

Smoking has been recognized as one of the risk factors for COVID-19 in several studies and by the WHO $[3,4,29]$. This is an expected finding because smoking is a major determinant leading to vulnerability conditions for COVID-19, such as cardiovascular disorders and chronic lung disease. Based on this fact, scientific attention has focused on whether there is any potential relationship between COVID-19 morbidity and e-cigarettes. Various hypotheses have been generated about the greater tendency of e-cigarette users to exhibit a worse prognosis of COVID-19, yet there is limited information on this subject. Although the risk of young people getting infected by COVID-19 is relatively lower compared to older adults, considering the proportion of young people using e-cigarettes and the dual use of cigarettes and e-cigarettes in youth, it may be one of the major risk factors for health problems caused by COVID-19.

In fact, the findings obtained by Gaiha and coworkers (2020) [30] from the online national screening results from the 50 U.S. states, which were performed on 4351 13-24 years old teenagers and young adults in the USA in May 2020, confirm this situation. They highlighted that not only dual users but also e-cigarette users had an increased risk factor of having COVID-like symptoms in the past 30 days. One key result of this study, after findings were adjusted for number of major confounders such as sex, age, and obesity, is that those who only reported e-cigarette use or dual use with tobacco were at a five (95\% CI: 1.82-13.96) or seven (95\% CI: 1.98-24.55) times higher risk, respectively, of having a diagnosis of COVID-19 compared to non-users.

Previous studies have shown that smokers are twice as likely as nonsmokers to contract influenza and have more severe symptoms. Moreover these studies indicated that smokers also experienced higher mortality in the past MERS-CoV outbreak [31,32]. The smokers are belived to be prone in terms of showing COVID-19 symptoms and likely to be taken to the intensive care. In this regards, compared to nonsmokers, smokers have been identified as 1.4 times more likely to have severe COVID-19 and 2.4 times been to the intensive care unit by requiring assisted ventilation, or die [3]. Studies conducted in the last year, when COVID-19 was widespread, report that many findings previously obtained for cigarettes are similar to those for e-cigarettes, both of which may cause lung inflammation and increased susceptibility to pulmonary viral and bacterial infections. Tobacco e-cigarette use is a possible COVID-19 risk factor [33].

Similar to tobacco smoker's chronic exposure, e-cigarettes disrupt renin-angiotensin system (RAS) homeostasis by inhibiting local compensatory mechanisms, resulting in an increased susceptibility to pulmonary and cardiovascular distress thereby potentially increasing the risk of COVID-19. Reidel and coworkers (2018) found that among e-cigarette users, there is an important increase in MUC4, a membraneanchored mucin, and an increase in the ratio of secretory mucins MUC5AC to MUC5B compared to non-users [34]. Tsai and coworkers (2018) investigated whether e-cigarette use may promote apoptosis-associated specklike protein containing caspase activation and recruitment domain (ASC) release into the lungs. ASC in bronchoalveolar lavage fluid (BALF) is higher in e-cigarette users and cigarette smokers. No statistical difference was seen between ASC levels of e-cigarette users and cigarette smokers. Levels of Caspase-1 and IL-1 $\beta$ are higher in smokers compared to e-cigarette users and nonsmokers [35].

The role of a7 nicotinic acetylcholine receptor (nAChRa7) might be substantial in the inflammatory responses induced by e-cigarette aerosols containing nicotine. Wang and coworkers (2020) investigated whether sub-chronic exposure to e-cigarettes induces an inflammatory response and dysregulated repair/extracellular matrix (ECM) remodeling, which takes place through nAChRa7. In this study, adult wild-type (WT), lung epithelial cell-specific $\mathrm{KO}$ (nAChRa7 CreCC10) and nAChRa7 knockout (KO) mice were used and BALF and lung tissues were examined. Sub-chronic exposure to e-cigarettes containing nicotine increased the inflammatory cellular influx of macrophages and T-lymphocytes and pro-inflammatory cytokines in BALF and caused an increase in the SARS-CoV-2 ACE2 receptor. However, in nAChRa7 KO mice, a reduction in inflammatory responses associated with decreased ACE2 receptor was seen. Wang and coworkers (2020) concluded that e-cigarette aerosols containing nicotine cause lung inflammation because of an altered repair response and ECM remodeling mediated by $\mathrm{nAChRa7,} \mathrm{which} \mathrm{is} \mathrm{thought} \mathrm{to} \mathrm{be} \mathrm{an} \mathrm{important}$ target [36].

Lee and coworkers (2020) investigated the potential association between vaping/smoking and the dysregulation of key genes and pathways related to COVID-19. It was reported that smoking, but not vaping, upregulates ACE2. Both smoking and nicotine and flavor-containing e-cigarettes result in the upregulation of pro-inflammatory cytokines and inflammasome-related genes. Chemokines including CXCL8 and CCL20 are 
upregulated in smokers, whereas CCR1 and CCL5 are upregulated in flavor/nicotine-containing e-cigarette users. In addition, genes implicated in inflammasomes, such as CXCL1, CXCL2, NOD2, and ASC, are upregulated in smokers and e-cigarette users. In contrast, vaping flavor and nicotine-free e-cigarettes did not cause significant cytokine dysregulation or inflammasome activation. It is concluded that smoking or vaping might substantially worsen COVID-19-associated inflammation or increase susceptibility to COVID-19 [27].

\section{VAPING-INDUCED LUNG INJURY (EVALI) AND COVID-19}

Acute eosinophilic pneumonia (AEP), lipoid pneumonia, and acute lung injury (ALI) induced by ecigarette use have been reported $[14,37,38]$. EVALI is a condition of acute or subacute lung injury with various findings ranging from mild respiratory symptoms to severe lung disease like organizing pneumonia to diffuse alveolar damage. A total of 2.807 EVALI cases have been reported to the CDC as of February 18, 2020, and among those, there have been 68 deaths [39]. EVALI is most often associated with the use of cannabis-based ENDS products. Results of recent EVALI cases have shown that vitamin E acetate, an additive found in some tetrahydrocannabinol containing vaping products, is strongly linked to EVALI outbreaks. It may present with new onset respiratory symptoms linked to vaping-related behavior within 90 days before symptom onset and a new infiltrative finding on either CT scan or chest radiograph [40]. Other infectious or plausible causes should be excluded. Pathophysiological processes of EVALI patients show heterogeneity [41]. EVALI is encountered as a spectrum of illnesses involving diffuse alveolar hemorrhage, respiratory-bronchiolitis interstitial lung disease, lipoid pneumonia, and acute eosinophilic pneumonia [42]. Similar clinical and radiographical findings can be found both in COVID-19 and EVALI. Findings of EVALI can overlap with COVID-19 pneumonia, which is why it is important for clinicians to consider this possibility [43].

It has been reported very recently that pulmonary imaging findings from e-cigarette users, EVALI, and COVID-19 may be similar [44]. Though COVID-19 and EVALI have related characteristic CT manifestations that mostly can be differentiated in their classic forms, when presented with overlapping imaging features, the distinction is of great importance, which might be hard due to symptoms common in both disorders such as shortness of breath, cough, fever and gastrointestinal symptoms [43]. When typical COVID-19 chest CT images are considered, ground glass opacities in a peripheral and subpleural distribution, multilobular involvement, and a slightly lower lung predominance are seen. The presence and increase in number and size of consolidation areas might be seen through the course of the disease. Interlobular septal thickening along with ground glass opacities is a common finding. Imaging patterns of EVALI can be variable, which are classified as acute eosinophilic pneumonia, hypersensitivity pneumonitis, diffuse alveolar damage, lipoid pneumonia, and organizing pneumonia, but among these, organizing pneumonia is the imaging pattern that most overlaps with COVID-19. Involvement of the lung periphery and general lack of pleural effusion can be seen in both cases but the existence of significant subpleural sparing suggests considering the organizing pneumonia subtype of EVALI rather than COVID-19 [43].

Pulmonary diseases with inflammatory characteristics generally increase serum CRP levels in response to inflammatory cytokines such as IL-1, IL-6, or TNF-a. Recently, it is claimed that in patients with COVID-19, admission CRP levels correlated with disease severity and tended to be a good predictor of adverse outcomes [45]. Similarly, high CRP concentrations were detected in EVALI patients [46].

\section{COVID-19, E-CIGARETTES, AND SOCIAL FACTORS}

Sussman and coworkers (2021) [47] reported in their review that there is a possibility of aerial virus transmission through exhaled bioaerosols including from e-cigarettes and it could translate into an extra risk of COVID-19 contamination. Indirect transmission via aerosols may occur across longer distances than conventional droplets. Aerial transmission of the coronavirus through environmental e-cigarette aerosols exhaled by infected vapers has not been studied comprehensively yet, but this issue remains a serious potential area for discussion. During the course of the pandemic, people were obliged to share limited indoor and outdoor spaces at various levels of home confinement and mobility constraints. While this situation decreased personal contacts in large populations, it also increased close contact both in space and time within small groups such as families.

The consumption of e-cigarettes entails frequent repetitive physical contact between the users' hands, mouth, and e-cigarette device. They have to remove their face masks to be able to use an e-cigarette in a public setting. Because of these factors, the person would be at higher risk of both contracting the virus when exposed to a contaminated environment and transmitting it to others. When individuals share a device with others, the 
risk amplifies further [48]. There are also behavioral changes influenced by the various aspects of the psychological impacts of the pandemic. Forced isolation has led to anxiety and depression, possibly leading to a rise in the intake of psychoactive substances, including nicotine products and e-cigarettes. At the same time, the COVID-19 pandemic has caused some direct behavioral changes in e-cigarette consumption patterns. Some of the most common alterations are: stocking up and bulk purchasing, changes in obtaining e-cigarette supplies, alternative purchasing procedures, increased e-cigarette usage, and disruption of routine and ecigarette use. The authors concluded that users of e-cigarette may experience or perceive additional COVID19 impacts, such as increased exposure, health risks, stress and financial burdens [49]. Some countries, such as Spain and Turkey (as of 12 November 2020), reacted to this situation by imposing smoking and vaping bans in outdoor public open spaces [50].

\section{CONCLUSION}

The global COVID-19 pandemic, which was declared a worldwide epidemic in March 2020, is an important public health problem that threatens men and women in all societies. Because there are several animal reservoirs of coronaviruses other than humans, it is unlikely that the disease will be eradicated, at least in the near future. In contrast, a former major killer, smallpox, only had a reservoir in humans and was declared eradicated in 1980. However, the coronavirus problem will stay with us for a time. Therefore, it is important to apply preventive measures and prepare by keeping immunity high and avoiding various risk factors that may weaken resilience and increase vulnerability to threatening infectious agents. Rationally, the COVID-19 epidemic should be perceived as a great opportunity for all societies to quit the usage of tobacco and it's products, especially cigarettes and e-cigarettes. The relationship between COVID-19 and e-cigarette use is a multifaceted problem. First, e-cigarette consumption may make users vulnerable to SARS-CoV-2 infection and its complications. Secondly, the aerosols exhaled by vapers may enhance the aerial viral transmission as a vehicle. And thirdly, the pandemic itself may promote the intensified utilization of ecigarettes because of the peculiar psychological stress burden. It should also be considered as an opportunity for health authorities, governments, and non-governmental organizations to motivate efforts to quit tobacco products in society.

Author contribution: Concept - İ.Ç.; Design - İ.Ç.; Supervision - İ.Ç.,İİ.,M.Y.; Literature Search - İ.Ç.,İİ.,M.Y.; Writing Manuscript - İ.Ç.,İİ̇,M.Y. Critical Review - İ.Ç.,İI.̇.,M.Y.

Conflict of interest statement: The authors declared no conflict of interest.

\section{REFERENCES}

[1] Harapan H, Itoh N, Yufika A, Winardi W, Keam S, Te H, Megawati D, Hayati Z, Wagner AL, Mudatsir M. Coronavirus disease 2019 (COVID-19): A literature review. J Infect Public Health. 2020; 13: 667-673. [CrossRef]

[2] Zhou M, Zhang X, Qu J. Coronavirus disease 2019 (COVID-19): a clinical update. Front. Med. 2020; 14: 126-135. [CrossRef]

[3] Vardavas CI, Nikitara K. COVID-19 and smoking: a systematic review of the evidence. Tob Induc Dis. 2020; 18: 20. [CrossRef]

[4] Patanavanich R, Glantz SA. Smoking is associated with worse outcomes of COVID-19 particularly among younger adults: A systematic review and meta-analysis. medRxiv [Preprint] 2020. [CrossRef]

[5] Egbe CO, Ngobese SP. COVID-19 lockdown and the tobacco product ban in South Africa. Tob Induc Dis. 2020; 18: 39. [CrossRef]

[6] Göney G, Çok İ, Tamer U, Burgaz S, Şengezer T. Urinary cotinine levels of electronic cigarette (e-cigarette) users. Toxicol Mech Methods. 2016; 26(6): 441-445. [CrossRef]

[7] Han S, Chen H, Zhang X, Liu T, Fu Y. Levels of selected groups of compounds in refill solutions for electronic cigarettes. Nicotine Tob Res. 2016; 18(5): 708-714. [CrossRef]

[8] Beauval N, Antherieu S, Soyez M, Gengler N, Grova N, Howsam M, Hardy EM, Fischer M, Appenzeller BMR, Goossens JF, Allorge D, Garcon G, Lo-Guidice JM, Garat A. Chemical evaluation of electronic cigarettes: multicomponent analysis of liquid refills and their corresponding aerosols. J Anal Toxicol. 2017; 41: 670-678. [CrossRef] 
[9] Goniewicz ML, Knysak J, Gawron M, Kosmider L, Sobczak A, Kurek J, Prokopowicz A, Jablonska-Czapla M, RosikDulewska C, Havel C, Jacob P 3rd, Benowitz N. Levels of selected carcinogens and toxicans in vapour from electronic cigarettes. Tob Control. 2014; 23(2): 133-139. [CrossRef]

[10] Olmedo P, Goessler W, Tanda S, Grau-Perez M, Jarmul S, Aherrera A, Chen R, Hilpert M, Cohen JE, Navas-Acien A, Rule AM. Metal concentrations in e-cigarette liquid and aerosol samples: the contribution of metallic coils. Environ Health Perspect. 2018; 126(2): 027010. [CrossRef]

[11] Madison MC, Landers CT, Gu BH, Chang CY, Tung HY, You R, Hong MJ, Baghaei N, Song LZ, Porter P, Putluri N, Salas R, Gilbert BE, Levental I, Campen MJ, Corry DB, Kheradmand F. Electronic cigarettes disrupt lung lipid homeostasis and innate immunity independent of nicotine. J Clin Invest. 2019; 129(10): 4290-4304. [CrossRef]

[12] Wang TW, Gentzke A, Sharapova S, Cullen KA, Ambrose BK, Jamal A. Tobacco product use among middle and high school students - United States, 2011-2017. MMWR Morb Mortal Wkly Rep. 2018; 67(22): 629-633. [CrossRef]

[13] Tackett AP, Keller-Hamilton B, Smith CE, Hébert ET, Metcalf JP, Queimado L, Stevens EM, Wallace SW, McQuaid EL, Wagener TL. Evaluation of respiratory symptoms among youth e-cigarette users. JAMA Netw Open. 2020; 3(10): e2020671. [CrossRef]

[14] McCauley L, Markin C, Hosmer D. An unexpected consequence of electronic cigarette use. Chest 2012; 141(4): 11101113. [CrossRef]

[15] McConnell R, Barrington-Trimis JL, Wang K, Urman R, Hong H, Unger J, Samet J, Leventhal A, Berhane K. Electronic cigarette use and respiratory symptoms in adolescents. Am J Respir Crit Care Med. 2017; 195(8): 1043-1049. [CrossRef]

[16] Wang MP, Ho SY, Leung LT, Lam TH. Electronic cigarette use and respiratory symptoms in Chinese adolescents in Hong Kong. JAMA Pediatr. 2016; 170(1): 89-91. [CrossRef]

[17] Cho JH, Paik SY. Association between electronic cigarette use and asthma among high school students in South Korea. PLoS One 2016; 11(3): e0151022. [CrossRef]

[18] Wills TA, Pagano I, Williams RJ, Tam EK. E-cigarette use and respiratory disorder in an adult sample. Drug Alcohol Depend. 2019; 194: 363-370. [CrossRef]

[19] Hedman L, Backman H, Stridsman C, Bosson JA, Lundback M, Lindberg A, Rönmark E, Ekerljung L. Association of electronic cigarette use with smoking habits, demographic factors, and respiratory symptoms. JAMA Netw Open 2018; 1(3): e180789. [CrossRef]

[20] Layden JE, Ghinai I, Pray I, Kimball A, Layer M, Tenforde MW, Navon L, Hoots B, Salvatore PP, Elderbrook M, Haupt T, Kanne J, Patel MT, Saathoff-Huber L, King BA, Schier JG, Mikosz CA, Meiman J. Pulmonary illness related to e-cigarette use in Illinois and Wisconsin - final report. N Engl J Med. 2020; 382(10): 903-916. [CrossRef]

[21] Schweitzer RJ, Wills TA, Tam E, Pagano I, Choi K. E-cigarette use and asthma in a multiethnic sample of adolescents. Prev Med. 2017; 105: 226-231. [CrossRef]

[22] Reid KM, Forrest JR, Porter L. Tobacco product use among youths with and without lifetime asthma - Florida, 2016. MMWR Morb Mortal Wkly Rep. 2018; 67(21): 599-601. [CrossRef]

[23] Wang JB, Olgin JE, Nah G, Vittinghoff E, Cataldo JK, Pletcher MJ, Marcus GM. Cigarette and e-cigarette dual use and risk of cardiopulmonary symptoms in the Health eHeart Study. PLoS One. 2018; 13(7): e0198681. [CrossRef]

[24] Ghosh A, Coakley RD, Ghio AJ, Muhlebach MS, Esther CR Jr, Alexis NE, Tarran R. Chronic e-cigarette use increases neutrophil elastase and matrix metalloprotease levels in the lung. Am J Respir Crit Care Med. 2019; 200(11): 13921401. [CrossRef]

[25] Miyashita L, Foley G. E-cigarettes and respiratory health: the latest evidence. J Physiol. 2020; 598(22): 5027-5038. [CrossRef]

[26] Temas D, Meyer A. E-cigarette- and vaping- related lung injury (EVALI) at a regional hospital system in South Carolina. Case Rep Pulmonol. 2020; 2020: 5370606. [CrossRef]

[27] Lee AC, Chakladar J, Li WT, Chen C, Chang EY, Wang-Rodriguez J, Ongkeko WM. Tobacco, but not nicotine and flavor-less electronic cigarettes, induces ACE2 and immune dysregulation. Int J Mol Sci. 2020; 21(15): 5513. [CrossRef]

[28] Rowell TR, Tarran R. Will chronic e -cigarette use cause lung disease? Am J Physiol Lung Cell Mol Physiol. 2015; 309(12): L1398-1409. [CrossRef]

[29] World Health Organization (WHO). Smoking and COVID-19. https://www.who.int/newsroom/commentaries/detail/smoking-and-covid-19 (accessed March 01, 2021). 
[30] Gaiha SM, Cheng J, Halpern-Felsher B. Association between youth smoking, electronic cigarette use, and COVID-19. J Adolesc Health. 2020; 67(4): 519-523. [CrossRef]

[31] Park JE, Jung S, Kim A, Park JE. MERS transmission and risk factors: a systematic review. BMC Public Health. 2018; 18(1): 574. [CrossRef]

[32] Arcavi L, Benowitz NL. Cigarette smoking and infection. Arch Intern Med. 2004; 164(20): 2206-2216. [CrossRef]

[33] Pino LE, Trianna I, Perez C, Piotrostanalzki A, Ruiz- Patino A, Lopes G, Cardona AF. Electronic nicotine delivery systems (ECs) and COVID-19: the perfect storm for young consumers. Clin Transl Oncol. 2021; 23(1): 5-9. [CrossRef]

[34] Reidel B, Radicioni G, Clapp PW, Ford AA, Abdelwahab S, Rebuli ME, Haridass P, Alexis NE, Jaspers I, Kesimer M. E-Cigarette use causes a unique innate immune response in the lung, involving increased neutrophilic activation and altered mucin secretion. Am J Respir Crit Care Med. 2018; 197(4): 492-501. [CrossRef]

[35] Tsai M, Song MA, McAndrew C, Brasky TM, Freudenheim JL, Mathe E, McElroy J, Reisinger SA, Shields PG, Wewers MD. Electronic versus combustible cigarette effects on inflammasome component release into human lung. Am J Respir Crit Care Med. 2019; 199(7): 922-925. [CrossRef]

[36] Wang Q, Sundar IK, Li D, Lucas JH, Muthumalage T, McDonough SR, Rahman I. E-cigarette-induced pulmonary inflammation and dysregulated repair are mediated by nAChR a7 receptor: role of nAChR a7 in SARS -CoV-2 COVID-19 ACE2 receptor regulation. Respir Res. 2020; 21(1): 154. [CrossRef]

[37] Kamada T, Yamashita Y, Tomioka H. Acute eosinophilic pneumonia following heat-not-burn cigarette smoking. Respirol Case Rep. 2016; 4(6): e00190. [CrossRef]

[38] Itoh M, Aoshiba K, Herai Y, Nakamura H, Takemura T. Lung injury associated with electronic cigarettes inhalation diagnosed by transbronchial lung biopsy. Respirol Case Rep. 2017; 6(1): e00282. [CrossRef]

[39] Centers for Disease Control and Prevention (CDC) Outbreak of Lung Injury Associated with the Use of E-Cigarette, or Vaping, Products. https://www.cdc.gov/tobacco/basic_information/e-cigarettes/severe-lungdisease.html\#latest-information (accessed April 01, 2021).

[40] Belok SH, Parikh R, Bernardo J, Kathuria H. E-cigarette, or vaping, product use-associated lung injury: a review. Pneumonia (Nathan). 2020; 12: 12. [CrossRef]

[41] Brown A, Balk SJ. E-cigarettes and other electronic nicotine delivery systems (ENDS). Curr Probl Pediatr Adolesc Health Care. 2020; 50(2): 100761. [CrossRef]

[42] Galo J, Celli D, Gross D, Holt G, Campos M. A presentation of e-cigarette vaping associated lung injury (EVALI) caused by THC-Containing electronic smoking device. Respir Med Case Rep. 2020; 31: 101154. [CrossRef]

[43] Ansari-Gilani K, Petraszko AM, Gilkeson RC. COVID-19 pneumonia versus EVALI, distinguishing the overlapping CT features in the COVID-19 era. Heart Lung. 2020; 49(6): 885-886. [CrossRef]

[44] Patel VN, Rouse M, Brown C, Pandya S. Ground glass opacities observed in a 26-year-old coronavirus disease 2019 (COVID-19) rule-out patient with a history of vape use. Cureus. 2020; 12(9): e10302. [CrossRef]

[45] Luo X, Zhou W, Yan X, Guo T, Wang B, Xia H, Ye L, Xiong J, Jiang Z, Liu Y, Zhang B, Yang W. Prognostic value of C-reactive protein in patients with Coronavirus 2019. Clin Infect Dis. 2020; 71(16): 2174-2179. [CrossRef]

[46] Kalininskiy A, Bach CT, Nacca NE, Gingsberg G, Marraffa J, Navarette KA, McGraw MD, Croft DP. E-cigarette, or vaping, product use associated lung injury (EVALI): case series and diagnostic approach. Lancet Respir Med. 2019; 7(12): 1017-1026. [CrossRef]

[47] Sussman RA, Golberstein E, Polosa R. Aerial transmission of the SARS-CoV-2 virus through environmental ecigarette aerosols: implications for public policies. Int J Environ Res Public Health. 2021; 18(4): 1437.[CrossRef]

[48] Hopkins DB, Al-Hamdani M. Young Canadian e-cigarette users and the COVID-19 pandemic: examining vaping behaviors by pandemic onset and gender. Front Public Health. 2021; 8: 620748. [CrossRef]

[49] Soule EK, Mayne S, Snipes W, Guy MC, Breland A, Fagan P. Impacts of COVID-19 on electronic cigarette purchasing, use and related behaviors. Int J Environ Res Public Health. 2020; 17(18): 6762. [CrossRef]

[50] Andreu-Mondon M, Barrio-Gimenez P, Mondon-Vehils S. COVID-19 and restrictions on tobacco use. Med Clin (Barc). 2021; 156(2): 93 ( article in English and in Spanish). [CrossRef] 